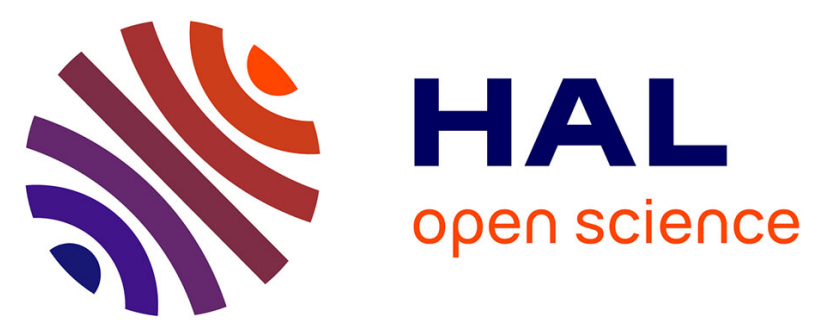

\title{
Process-based analysis of Thinopyrum intermedium phenological development highlights the importance of dual induction for reproductive growth and agronomic performance
}

Olivier Duchene, Benjamin Dumont, Douglas J Cattani, Laura Fagnant, Brandon Schlautman, Lee R Dehaan, Spencer Barriball, Jacob M Jungers, Valentin D Picasso, Christophe David, et al.

\section{- To cite this version:}

Olivier Duchene, Benjamin Dumont, Douglas J Cattani, Laura Fagnant, Brandon Schlautman, et al.. Process-based analysis of Thinopyrum intermedium phenological development highlights the importance of dual induction for reproductive growth and agronomic performance. Agricultural and Forest Meteorology, 2021, 301-302, pp.108341. 10.1016/j.agrformet.2021.108341 • hal-03185081

\author{
HAL Id: hal-03185081 \\ https://hal.science/hal-03185081
}

Submitted on 22 Nov 2021

HAL is a multi-disciplinary open access archive for the deposit and dissemination of scientific research documents, whether they are published or not. The documents may come from teaching and research institutions in France or abroad, or from public or private research centers.
L'archive ouverte pluridisciplinaire HAL, est destinée au dépôt et à la diffusion de documents scientifiques de niveau recherche, publiés ou non, émanant des établissements d'enseignement et de recherche français ou étrangers, des laboratoires publics ou privés. 
1 Process-based analysis of Thinopyrum intermedium phenological development

2 highlights the importance of dual induction for reproductive growth and agronomic

3

4

5 Olivier Duchene ${ }^{1 \S}$, Benjamin Dumont ${ }^{2 \S}$, Douglas J. Cattani ${ }^{3}$, Laura Fagnant $^{2}$, Brandon Schlautman $^{4}$,

6 Lee R. DeHaan ${ }^{4}$, Spencer Barriball ${ }^{4}$, Jacob M. Jungers ${ }^{5}$, Valentin D. Picasso ${ }^{6}$, Christophe David ${ }^{1}$, Florian

7 Celette $^{1}$

8

9

10

11

12

13

14

15

16

17

\section{${ }^{\S}$ The authors contributed equally to the paper}

*corresponding author: olduchene@isara.fr; +33631460196

${ }^{1}$ ISARA, Agroecology and Environment Research Unit, 23 Rue Jean Baldassini, 69364, Lyon cedex 07, France

${ }^{2}$ ULiege - Gembloux AgroBio-Tech, Plant Sciences Axis, Crop Science lab., B- 5030 Gembloux, Belgium

${ }^{3}$ Department of Plant Science, University of Manitoba, 66 Dafoe Road, Winnipeg, Manitoba, Canada R3T 2 N2.

${ }^{4}$ The Land Institute, 2440 E. Water Well Rd., Salina, KS, 67401, USA

${ }^{5}$ Department of Agronomy and Plant Genetics, University of Minnesota, St. Paul, MN 55108, USA

${ }^{6}$ Department of Agronomy, University of Wisconsin - Madison, 1575 Linden Dr., Madison, WI, 53706, USA

\section{Keywords}

Thinopyrum intermedium; perennial grains; flowering induction; photoperiod; modelling

\section{Highlights}

- IWG reproductive growth requires a vernalization treatment

- In spring, IWG reproductive growth is associated with GDD accumulation and photoperiodic response

- GDD-daylength coupled dynamics drive IWG sward functional changes during reproductive growth

- GDD-daylength coupled dynamics can inform and improve agronomic management. 
Intermediate wheatgrass (Thinopyrum intermedium (Host) Barkworth \& D.R. Dewey) is being developed for use as a new perennial grain crop through breeding and agronomic research. However, progress has been hampered by lack of understanding of environmental requirements for flowering and grain production. Therefore, we developed a phenology model for IWG adapted from the STICS soil-crop model. The model was compliant with experimental results (relative root mean square error $=0.03)$. The optimal vernalizing temperature was between 4 and $5^{\circ} \mathrm{C}$, optimal daylength between 13 and $14 \mathrm{~h}$, while daylength below $11 \mathrm{~h}$ slowed reproductive development. Vernalization requirement was found to be a constraining inductive process. Including a photoperiod limitation to the model with temperature improved its ability to predict induction at various latitudes. Therefore, timing and duration of vegetative vs. reproductive growth may differ between environments and change reproductive tiller elongation earliness, weed competitiveness, management timing, and stress conditions during phases critical to grain yield. Accurate phenology models will enable optimal field management and inform future breeding strategies. However, plasticity may lead to divergent ideotypes under various agroecosystems.

\section{Introduction}

The wheat-relative intermediate wheatgrass (Thinopyrum intermedium (Host) Barkworth \& D.R. Dewey) (IWG) is a winter-hardy cool-season perennial grass, which has recently undergone development as a perennial grain by several breeding programs (Bajgain et al., 2020). Improved IWG populations have been released by The Land Institute (Salina, Kansas, USA) under the trade name Kernza ${ }^{\circledR}$ (DeHaan et al., 2018). Intermediate wheatgrass can support the transition to agroecological systems because this perennial crop produces forage and grain for several years with minimal soil disturbance and associated environmental issues (Duchene et al., 2019; Ryan et al., 2018). Featuring large and deep roots, year-round soil cover, increased resource use efficiency and an extended growing season (Cattani and Asselin, 2018a; DeHaan, 2015; Glover et al., 2010; Sprunger et al., 2018), 
the 'perennialization' of cropping systems would be one cornerstone of sustainable agriculture (Crews, 2016).

Intermediate wheatgrass has relatively low grain yields compared with annual cereal grains (Jungers et al., 2018, 2017; Tautges et al., 2018), which has limited the introduction and adoption of IWG into grain systems and crop rotations. Seed production is the result of the interaction between genotype and growth conditions. Breeding efforts have been mostly dedicated to improving shatter resistance and free-threshing seeds, along with larger seed mass and seed number per head (DeHaan et al., 2018). Little attention has been paid to IWG phenological milestones that determine its growth cycle (inductive transition), from the initiation of inflorescence primordia to seed maturity. Current worldwide endeavors and interest in IWG production is driving the need for deeper investigation of the environmental requirements associated with IWG yield and yield components. Filling this knowledge gap would provide direction in targeting specific breeding strategies, suitable growing contexts, and best crop management practices to optimize IWG grain production.

Winter annual herbaceous grains, like winter wheat, and most perennial grasses have a dual induction requirement for flowering (Cooper and Calder, 1964; Heide, 1994). The primary induction includes exposure to winter conditions, including low temperatures (LT) and short daylength (SD), which is followed by a secondary induction that includes a period of transition to longer days (LD) and higher temperatures (HT; Heide, 1994). Primary induction is usually discussed as the vernalization process, corresponding to a chilling treatment that induce reproductive primordia (Seppänen et al., 2013). Cold resistance is gradually improved through low-temperature acclimation, and then gradually lost with time, cooler temperatures and vernalization saturation (Fowler et al., 1996; Limin and Fowler, 2006). The secondary induction follows as a critical accumulation of heat units (growing degree-day) and increased daylengths that stimulate a crop's phasic development, tiller growth and flowering (Basu et al., 2012; Chouard, 1960; Trione and Metzger, 1970). 
In winter grain crops and forage grasses, the achievement of primary induction (vernalization) needs either LT or SD, but sometimes requires both (e.g. Bromus inermis), or has a preferential temperature/photoperiod inductive pathway (e.g. Phleum nodosum, Agrostis canina; Cooper and Calder, 1964; Halevy, 1989). Temperature and photoperiod are interactive factors since a change in one parameter can modify inductive requirements of the other (Halevy, 1989; Heide, 1994; Limin and Fowler, 2006; Mahfoozi et al., 2000; Ritchie, 1991). However, warm-season perennial grasses (e.g. Panicum virgatum, Andropogon gerardii), and certain cool-season species (e.g. Phleum pratense) do not require vernalization to achieve flowering (Table S1). Moreover, population diversity, breeding, and plant life-history in fields leads to a certain variability or heterogeneity of inductive requirements among the same species, with the potential formation of cultivars or local ecotypes (Dubcovsky et al., 2006 Cooper and Calder, 1964; Jokela et al., 2015; Palit et al., 2014). Considering IWG, the need of primary induction (vernalization treatment) to ensure proper reproductive growth has been shown previously (Frischknecht, 1959) and has been recently confirmed by field observations and results from controlled experiments (Ivancic et al, under review).

The transition from winter dormancy to spring growth and flowering (secondary induction) vary greatly among perennial grasses in terms of timing and environmental requirements (Ansquer et al., 2009). Flowering earliness generally differentiates fast growing species with generally lower requirements. Conversely, late maturing species generally require greater heat unit accumulation, associated with higher phyllochrons, to achieve flowering (Duru et al., 1993, 2008b; Frank and Bauer, 1995). Photoperiod mediation of the growth period is observable in many species, with different degrees of importance, late flowering and single induction grasses would depend solely on photoperiod responsiveness (Castro et al., 2011; Esbroeck et al., 2003; Mitchell et al., 1997). 
would have been a driver of later tiller elongation as compared to other perennial grasses such as Bromus inermis (Mitchell et al., 1998).

Linking plant phenology to whole plant growth and resource use strategy, fast or slow growing patterns of forage grasses appears to be associated with several functional traits (e.g. organ turnover rate, specific leaf area, biomass density, leaf nitrogen concentration, net primary productivity; Cruz et al., 2010; Duru et al., 2008, 2009; Ryser and Lambers, 1995; Shipley, 2006) which, when combined, determine the resource-conservative or acquisitive growth strategies of these grass species in their native ecosystems.

This study used a large pool of phenological field observations from various regions and across different cropping seasons to evaluate IWG phasic development in situ. To complement other studies designed in controlled conditions (Ivancic et al., under review), this dataset offers an unprecedented opportunity to look at the influence of divergent temperature and daylength conditions on IWG growth. The use of integrative crop modelling concepts is then a powerful way to provide a more holistic understanding of the crop growth dynamic within a specific environment. Coupling field observations and modeling approaches notably enables the analysis of complex biotic and abiotic interactions through the integration of growth function and process-based data.

The objective was to accurately characterize the converging drivers of phenological development of IWG populations in diverse growth environments. In particular, three questions were addressed: i) How sensitive is IWG to vernalization and what are its vernalization requirements?; ii) How sensitive is IWG to photoperiod during secondary induction and what are the photoperiod thresholds of IWG?; and iii) How fast does IWG develop in various agronomic conditions? These questions were examined through field-based measurement analysis and crop model inversion of IWG phenological development. IWG phenology and environmental requirements are discussed and compared to the 
existing literature on perennial grasses and annual winter grain crops, with the purpose to better place IWG growth among already characterized functional groups. Overall, this work aims to evaluate opportunities and challenges in terms of adequacy and integration of IWG as a perennial grain into farming systems.

\section{Materials and methods}

To characterize IWG phenological responses to contrasted growing environments, and compare its behavior to known perennial grasses or annual grain crops characterized in the literature (section 2.1), a database was constructed with experiments conducted across Western Europe and North America (section 2.2). In an attempt to better understand crop response to those conditions, field result analysis was coupled with crop modeling approaches. Classic field result analysis, consisting of comparing phenological stages and degree-day accumulation starting February 01 (shown to minimize GDD accumulation variability and corresponding to plant changes in assimilate allocation; Ansquer et al., 2009; Peacock, 1976), was first conducted (section 2.3). Crop modeling approaches were then deployed to further ascertain the impacts of vernalization and photoperiod on the phenological development (section 2.4).

\subsection{Experimental sites and data collection}

\subsubsection{Site description and experimental conditions}

From 2012 to 2019, IWG field experiments were conducted in four countries (USA, Canada, France and Belgium). Data were thus respectively collected under Köppen climate (Peel et al., 2007) type Dfb in Canada (humid continental climate conditions), type Dfa in the USA (hot summer continental climate conditions) and type Cfb in France and Belgium (temperate climatic conditions characterized by warm summers). These climatic contexts allowed evaluation of various temperature patterns and seasonal conditions to assess the accumulation of heat units and vernalization requirements. 
152 inducing contrasted photoperiods.

153

\subsubsection{Data collection}

For each location, precipitation and average temperatures were measured daily. IWG growth stages were measured at the field level, representing the dominant growth stage of the stand, and were rated using the $\mathrm{BBCH}$ scale (Hess et al., 1997) and the timing of each observation was reported in DAE/DAH unit (day after emergence/ day after last harvest). In this paper the focus was put on four main phenological stages:

- stem elongation (BBCH 30), which characterize the end the juvenile phase and the beginning of shoot development;

- flag leaf (BBCH 39) accounts for the end of foliar development;

- flowering (anthesis) (BBCH 65) represents the end of shoot development and the beginning of grain filling;

- maturity (BBCH 89), which stands for the end of grain filling and the cessation of the reproductive cycle.

A total of 137 phenological observations were recorded on these main phenological stages.

\subsection{Growing-degree-day calculation}

Following the approach of Ansquer et al. (2009), growing-degree-day (GDD) in base 0 was computed as: 
177 As in Ansquer et al. (2009), and as usually done for perennial crops, the sum of GDD is usually 178 computed starting Feb. 01 in France. In this paper, the sum of GDD was computed from February, 01 179 and accumulated up to flowering $(\mathrm{BBCH} 65)$. This approach has demonstrated its relevance to determine grass development milestones (Ansquer et al. 2009 ; Bartholomew and Williams, 2005 ; Brown et al., 1986 ; Chauvel et al., 2000 ; Frank and Hofmann, 1989 ; Mitchell et al., 1997). Using a constant base temperature over which any additional degree is accumulated as a temperature enabling developmental unit is largely used (e.g. Ansquer et al., 2004 ; Cruz et al., 2010 ; Duru et al., 2008c ; Luo et al. 2011 ; Parthasarathi et al., 2013). Such an approach has been integrated in most plant growth models (Wang et al., 2017).

\subsection{Crop modelling}

The crop model approach deployed in this paper adopts the formalisms used in the widely validated STICS soil-crop model (Brisson et al., 2009, 2002, 1998). We propose here a short description of the different formalisms. Further details are found in Brisson et al. (2009).

\subsubsection{Phenological development}

192

193

194

As for many crop models, the simulation of succession of different phenological stages is driven by the accumulation of "development units". To compute these, we kept from the STICS model the impacts of temperature, photoperiod and cold requirements, while we set aside the slowing impacts of water and nitrogen stress. The development units considered here are computed at the daily time step as follows:

In which $i$ is the considered day, UPVT are Photo-Vernalo-Thermic Units (UPVT in short), GDD $D_{t}$ are the growing degrees-days limited by thresholds, SFP is a Slowdown Factor accounting for Photoperiod, and $S F V$ is a Slowdown Factor accounting for Vernalization. 
Under this formalization, the accumulation of development units is firstly driven by the widelyaccepted concept of growing degrees-days (Durand, 1967). Comparing to the simple Eq. 2, the concept of growing degree-day used here $\left(\mathrm{GDD}_{\mathrm{t}}\right)$ is adapted to account for minimal, optimal and maximal temperature thresholds (Eq. 4). Photoperiod (Eq.5) and cold requirement (Eq.6) are used to slow down the accumulation of development units; as suggested by Brisson and Delecolle (1992), these effects are computed as a rate applied per unit of thermal time, implying the use of multiplicative terms in eq.3.

Finally, the last step of phenological development simulation was to sum UPVT over the cropping season. To do so, UPVT were summed starting from the day of emergence (establishment year) or the day following previous harvest (other years) up to the harvest of the considered crop season. Regarding the simulation of one particular stage $(\mathrm{BBCH} 30,39,65$ or 89 - see section "Data collection"), the model calibration involved retrieving the sum of UPVT that was required to reach a specific stage while optimizing the model performances (see section "Assessment of model performance").

\subsubsection{Effect of temperature}

The impacts of temperature respond to a triangular function (Eq.4)

$$
\left\{\begin{array}{clc}
G D D_{t}(i)=0 & \text { if } & T_{\text {mean }}(i) \leq D T_{\text {min }} \text { or } T_{\text {mean }}(i) \geq D T_{\text {max }} \\
G D D_{t}(i)=T_{\text {mean }}(i)-D T_{\text {min }} & \text { if } & D T_{\text {min }}<T_{\text {mean }}(i) \leq D T_{\text {opt }} \\
G D D_{t}(i)=\frac{D T_{\text {opt }}-D T_{\text {min }}}{D T_{\text {opt }}-D T_{\text {max }}} \cdot\left(T_{\text {mean }}(i)-D T_{\text {max }}\right) & \text { if } & D T_{\text {opt }}<T_{\text {mean }}(i)<D T_{\text {max }}
\end{array}\right.
$$

\section{Eq. 4}

In which $\mathrm{DT}_{\min }, \mathrm{DT}_{\text {opt }}$ and $\mathrm{DT}_{\max }$ are the minimal, optimal and maximal temperature to allow for crop development. In particular, here, $D T_{\min }$ is the equivalent of $\mathrm{T}_{\text {base }}$ proposed at equation 2.

Under such conditions, the effects of temperature on crop development are linearly increasing between $\mathrm{DT}_{\min }$ and $\mathrm{DT}_{\mathrm{opt}}$ and are linearly decreasing between $\mathrm{DT}_{\text {opt }}$ and $\mathrm{DT} \mathrm{T}_{\max }$. $\mathrm{DT} T_{\text {opt }}$ and $\mathrm{DT} T_{\max }$ have 
been proposed in Brisson et al. (2008) to account for the slowdown in crop development that can be observed under hot conditions.

\subsubsection{Photoperiod factor}

Using classic astronomical functions, the photoperiod (PhotoP(i) in Eq.5) can be calculated on the basis of the calendar days and the latitude (Sellers, 1965). Based on the photoperiod, the slow-down photoperiodic effect SFP(i) can then be calculated using Eq. 5 .

$$
\left\{\begin{array}{l}
\operatorname{SFP}(i)=\frac{\left(\text { PhotoP }(i)-\text { PhotoP }_{\text {sat }}\right)}{\left(\text { PhotoP }_{\text {sat }}-\text { PhotoP }_{\text {base }}\right)}+1 \\
S F P(i)=\max (\min (\operatorname{SFP}(i), 1), 0)
\end{array}\right.
$$

In which Photo $\mathrm{P}_{\text {base }}$ is the photoperiod below which there is no development and $\mathrm{PhotoP}_{\text {sat }}$ is the saturation photoperiod, above which there is no limitation. The second term of Eq.5 ensures that SFP(i) is mathematically bounded between 0 and 1.

We assumed that IWG would be a long-day plant (Heide, 1994) similar to other grassland species and most annual grain crops such as wheat, barley and rye. This implies that Photo $\mathrm{P}_{\text {base }}$ would be lower than PhotoP $\mathrm{P}_{\text {sat }}$. As for the STICS model, photoperiod effect was inactivated after flowering stage and up to maturity.

\subsubsection{Cold requirements}

The cold requirement routine is a two-step procedure, in which the vernalizing value of a given day is firstly computed (VV(i) in Eq.6), and then the slow-down factor SFV(i) is calculated as the ratio of completion of the total vernalization requirements (Eq.7). We furthermore adapted the formalism proposed in STICS to introduce a sensitivity parameter to vernalization, as for Eq. 5, to determine what would be the degree of sensitivity of IWG to vernalization requirement. 


$$
V V(i)=\max \left(1-\left[\frac{T_{\text {vern }}-T_{\text {mean }}(i)}{A m p l i_{\text {vern }}}\right]^{2}, 0\right) \quad \text { Eq. } 6
$$

$$
\left\{\begin{array}{c}
S F V(i)=\frac{\left[\sum_{j=D_{\text {emer }} \text { or } D_{\text {harv }}} V V(j)\right]-V V_{\text {min }}}{V V_{\text {req }}-V V_{\text {min }}} \\
S F V(i)=\max (\min (S F V(i), 1), 0)
\end{array}\right.
$$

In these equations, $T_{\text {vern }}$ is the temperature to reach an optimal vernalization value during a given day, Ampli $i_{\text {vern }}$ is the amplitude of the vernalizing effect, $D_{\text {emer }}$ and $D_{\text {harv }}$ are respectively the day of emergence (during the IWG establishment year) or the day of the last harvest (for any other year), $V V_{\text {min }}$ is the minimum number of vernalizing days (fixed at 1 for this analysis) and $V V_{\text {req }}$ is the total number of required vernalizing day. As for Eq.5, the second term of Eq.7 ensures that SFV (i) is mathematically bounded between 0 and 1 .

Therefore, once initiated $\left(\Sigma V V(i)>V V_{\text {min }}\right)$, the vernalization routine proposed in STICS considers that the "resting state" during winter time is not total and allows for a partial accumulation of development units. Furthermore, in this formalism, incomplete vernalization requirements $(\Sigma \mathrm{VV}(\mathrm{i})<$ $\mathrm{VV}_{\text {req }}$ ) would slow the development of crops but would thus allow evolving in the phenology, leading eventually to flowering and maturity at a slower rate, without stopping it and preventing ears to be fertile.

\subsubsection{Snow cover correction}

Due to their climatic conditions (climate type Dfb), Canadian sites are prone to significant snowfalls and snow cover during winter. As suggested by Jégo et al., (2014) using crop models in northern areas of Canada, Scandinavia or Russia requires accurately simulating the impacts of snow cover and soil freezing on soil processes, survival and growth of (perennial) crops. Snow cover indeed changes 
the energy budget of the soil surface by increasing the albedo, reducing the soil heat flux and the surface roughness, and modifying the soil temperature and water content profiles (Jégo et al., 2014). In their paper, previous authors compared three snow modules, more or less complex in their representation of snow accumulation and melting. As we did not require the same level of complexity, we considered a simpler approach based on a simple temperature threshold (Eq. 8). Based on records obtained at Winnipeg, Canada, experimental sites regarding air temperature and soil temperature (Fig. 1), a bilinear model was adjusted (Eq. 8).

$$
\left\{\begin{array}{cll}
T_{\text {corr }}(i)=T_{\text {mean }}(i) & \text { if } & T_{\text {mean }}(i)>0^{\circ} \mathrm{C} \\
T_{\text {corr }}(i)=0.165 . T_{\text {mean }}(i) & \text { if } & T_{\text {mean }}(i)<0^{\circ} \mathrm{C}
\end{array}\right.
$$

Within climate type $\mathrm{Dfb}$, this correction $\left(\mathrm{R}^{2}=0.369\right)$ was considered sufficient to mimic the impact of snow insulation, which in turn allowed proper estimates of the effective temperature sensed by the crop during the effective period of vernalization. Based on existing snow model (Jego et al., 2014) and the recorded data (Fig. 1), " $0^{\circ} \mathrm{C}$ " was considered a robust and coherent threshold. It was furthermore to constrain the regressions through the origins $[0,0]$. The slope of the trend on records reported in the upper right quadrant of Fig. S1 was quite logically forced to 1 , while the slope of the trend on records reported in the lower left quadrant was fit through automatic regression, resulting in a coefficient of 0.165 .

\subsection{Crop model inversion}

\subsubsection{The DREAM sampling algorithm}

Since the works of Metropolis (Metropolis et al., 1953) and later Hastings (1970), Bayesian approaches have greatly improved to sample the most relevant parameter posterior distribution, notably through the use of Markov Chain Monte Carlo (MCMC) simulations (Metropolis et al., 1953). While a lot of research was devoted to improve Metropolis-Hastings approach up to the late 1990's, 
algorithms remained long inefficient when confronted with very heavy tails posterior distribution and with posterior model output prediction surfaces that contained multiple local optima. Based on Ter Braak's work (2006), research was conducted that successively lifted the different limitations and enhanced considerably the efficiency of Bayesian MCMC genetic sampling procedures. The Differential Evolution Adaptive Metropolis (DREAM) algorithm developed by Vrugt et al. (2009) is a follow-up of the DE-MC method (Ter Braak, 2006), and integrates the advantages of the Shuffled Complex Evolution Metropolis (SCEM-UA) global optimization algorithm (Vrugt et al., 2003). of the DREAM algorithm have been published, e.g. in Vrugt et al. (2009) and Vrugt (2016). Recently, Dumont et al. (2014) coupled for the first time the DREAM algorithm with a complex crop model (STICS in this case). This section presents a summary of the algorithm but we refer to papers for a detailed description.

The advantages of DREAM are summarized here:

- DREAM incorporates a self-adaptive randomized subspace sampling routine;

- It can maintain a detailed balance and ergodicity that has proven effective to accommodate a heavy-tailed and multimodal target;

- It solves limitations such as the need to choose the starting values and the unlimited number

The last characteristic has been proven particularly effective in the case of crop model parameter sampling (Dumont et al., 2014). Indeed, in agricultural research, the (model) errors are most of the time correlated, non-stationary and non-Gaussian. As stated by Wallach et al. (2006), site-year 
measurements are performed at different dates in a given site-year, observations and (model) residuals will most often be auto-correlated.

\subsubsection{Sampling procedure}

With regard to the DREAM options, the toolbox ran a maximum of 5,000 evaluation functions multiplied by the number of sampled parameters. Preliminary tests concluded that convergence was easily ensured with such a rule. The number of Markov chains was fixed at two times the number of parameters to be sampled, following Vrugt et al. (2009). Following the observation made by Dumont et al. (2014), to improve the convergence of the algorithm when coupled with a crop model, a standard error was considered on recorded data to compute the likelihood function. It was decided to use a fixed sigma of 5 days, which is among the greatest standard error generally observed at $\mathrm{BBCH} 65$ due to the temporal sprawl of the flowering stage. Other options of the DREAM toolbox were kept as the original release.

The initial values and the prior distribution were determined as specified in Table 1, based on parameters as defined within the STICS model, literature review (Table S1) or expert knowledge. Other parameters of the phenology model were kept at a fixed value: $\mathrm{DT}_{\mathrm{opt}}$ and $\mathrm{DT}_{\max }$ were respectively fixed at 35 and $45^{\circ} \mathrm{C}$, and $\mathrm{VV}_{\min }$ was fixed at 1 equivalent-day

\footnotetext{
Table 1 : Table of the parameter being optimised
} 


\begin{tabular}{|c|c|c|c|}
\hline Parameter & Initial value & A priori & Origin of the initial value \\
\hline $\mathrm{DT}_{\min }$ & 0 & {$[0-15]$} & Grassland / Wheat STICS parameter \\
\hline $\mathrm{VV}_{\text {req }}$ & 35 & {$[20-100]$} & Grassland STICS parameter \\
\hline$T_{\text {vern }}$ & 5 & {$[-5-15]$} & Ryegrass STICS parameter \\
\hline Ampli $_{\text {vern }}$ & 7.5 & {$[1-20]$} & Ryegrass STICS parameter \\
\hline PhotoP $_{\text {base }}$ & 8 & {$[1-12]$} & Grassland / Wheat STICS parameter \\
\hline PhotoP $_{\text {sat }}$ & 20 & [13 - 24] & Grassland / Wheat STICS parameter \\
\hline$\Sigma \mathrm{UPVT}_{\mathrm{BBCH}}$ & 215 & {$[0-600]$} & Preliminary test \\
\hline$\Sigma \mathrm{UPVT}_{\mathrm{BBCH}}$ & 345 & [200 - 1000] & Preliminary test \\
\hline$\Sigma U^{\prime} V T_{\text {BBCH65 }}$ & 700 & [400 - 1200] & Preliminary test \\
\hline$\Sigma \mathrm{UPVT}_{\mathrm{BBCH} 89}$ & 1500 & {$[800-2000]$} & Preliminary test \\
\hline
\end{tabular}

\subsubsection{Data analysis and parameter uncertainty}

347

Assessing the posterior distribution of the model parameters using MCMC simulations, as performed with DREAM, lead to several chains that contained all the necessary information about model parameters.

We first analyzed the marginal posterior distribution function (PDF) to retrieve the main information regarding sampled parameters, i.e. the posterior means, medians, the main percentiles. We furthermore looked at the correlation coefficients between the generated parameter samples. To do so, the last 500 values of each chain, where stationarity had been achieved, were kept to process data.

To further use the crop model as research or decision-support tools, it is necessary to summarize the marginal posterior probability distribution function (PDF) in one parameter estimate. A first solution would be to select, among the chains, the parameter set that offers the optimal solution, i.e. the one that optimizes the convergence criterion. However, provided convergence has achieved a stationary distribution, from a statistical/methodological point of view, the information contained in each chain 
has statistically the same relevance. It was therefore decided to use the medians of the distributions to evaluate the overall model performance.

\subsubsection{Assessment of model performance}

There is a need to define criteria that will help determine whether or not a model is 'acceptable', in pursuit of set objectives and its ability to represent reality (Loague and Green, 1991). Three main statistical criteria were used to assess model performance namely the root mean square error (RMSE), the model efficiency (EF) and the normalized deviation (ND). These criteria are defined in equations 9,10 and 11.

$$
\begin{array}{ll}
R M S E=\sqrt{\frac{1}{n} \sum_{i=1}^{n}\left(y_{i}-\hat{y}_{i}\right)^{2}} & \text { Eq. } 9 \\
E F=1-\frac{\sum_{i=1}^{n}\left(y_{i}-\hat{y}_{i}\right)^{2}}{\sum_{i=1}^{n}\left(y_{i}-\bar{y}\right)^{2}} & \text { Eq. } 10 \\
N D=\frac{\sum_{i=1}^{n}\left(\hat{y}_{i}\right)-\sum_{i=1}^{n}\left(y_{i}\right)}{\sum_{i=1}^{n}\left(y_{i}\right)} & \text { Eq. } 11
\end{array}
$$

In these equations, $n$ is the number of observations, $y_{i}$ is the $i^{\text {th }}$ observation, $\bar{y}$ is the average of observation and $\hat{y}_{i}$ is the simulated value corresponding to the $\mathrm{i}^{\text {th }}$ observation.

RMSE, EF and ND are rarely used alone for evaluating model quality. Different authors (Beaudoin et al., 2008; Brisson et al., 2002; Dumont et al., 2014) used RMSE, EF and ND jointly, on the basis that model calibration or validation is accurate if the RMSE is relatively low compared with the mean of the observations, and if $\mathrm{EF}>0.5$ and $|\mathrm{ND}|<0.1$

\subsubsection{Iterative process-based modelling approach}

The crop model-based approach was used to pursue a two-fold objective

- First, following the literature regarding IWG (Mitchell et al., 1998, Ivancic et al, under review), the added-value of improving the temperature-driven phenological model with vernalization and photoperiod processes was assessed. Each process was activated sequentially. At each step, all model parameters related to the respectively activated formalisms were optimized on all site-year combinations (Table S2), including the data sets 
dedicated to validation. However, the data treatment was only focused on the global model performance. The idea driving this phase was to determine whether or not IWG phenological modelling demonstrated sensitivity to these processes, which would in turn corroborate the findings of field and controlled experiments.

- In a second phase, once the sensitivity of IWG phenological modelling to vernalization and photoperiod was determined, an actual calibration/validation process was launched. All relevant parameters were considered for sampling. In this second phase, data sets were respectively dedicated to either calibration or validation, as per Table S2. The objective of this phase was to create additional knowledge on IWG phenological development, by retrieving the most probable value of the parameters controlling the developmental processes.

The software programs (this phenological model and DREAM) are libraries of Matlab ${ }^{\circledR}$ functions. The full version of the current release of the STICS soil-crop model is accessible at 


\subsection{Growing-degree day accumulation to flowering from February 1 base $0^{\circ} \mathrm{C}$}

Table 2. Growing degree day accumulation from February 1 to flowering (base 0 )

\begin{tabular}{|c|c|c|}
\hline $\begin{array}{c}\text { Regions and } \\
\text { climate type }\end{array}$ & Mean (different letters denote statistical \\
differences across means)
\end{tabular}

408

409

410

411

Computing GDD accumulation from Feb 01 to flowering (using the simpler formalization of eq. 1 and 2) demonstrates a large variability (from 952 to 1885) between fields and years. These values cover most of the GDD range proposed by Cruz et al. (2010), hence belonging either to early, medium, or late forage grass species. Meanwhile, values are however clustered by growth regions. European conditions (Cfb Koppen climate classification) show the highest GDD values, while Canadian conditions (Dfb) represent the lowest and USA (Dfa) provides intermediate values. Therefore, GDD values are more likely relevant at a given regional scale to identify a plant growth pattern within the region, rather than useful to characterize the overall plant phenological drivers. This latter consideration highlights the need for more refined tools to simulate and evaluate IWG phenological growth.

\subsection{IWG sensitivity to vernalization and photoperiod induction processes}

First, the crop model approach (including an intermediate step of parameter sampling) was used to determine whether or not the temperature-driven phenological model would benefit from the vernalization and photoperiod response processes to reproduce the observations. Table 3 reports the overall model performances. The poor performance of the sole $\mathrm{GDD}_{\mathrm{t}}$ formalization confirms 
results presented at previous section. Adding the sole photoperiodic effect (SFP) did not improve

427 sufficiently the model performance; RMSE was marginally decreased and model efficiency remained

428 below the 0.5 threshold. The greatest improvement to model performance appeared when the vernalization process was activated (SFV). As observed, RMSE reached 10.06 days and model efficiency increased up to 0.97 . Finally activating the photoperiod response function in addition to the SFV provided an additional improvement in model performance, with the RMSE dropping to 7.5 days and model efficiency increasing slightly (0.98). At each step, a value of ND close to 0 is showing the algorithm tendency to avoid any under or overestimation (minimization of RMSE).

Table 3. Overall model performances considering the two induction processes

\begin{tabular}{|llll|}
\hline Model formalism & \multicolumn{3}{l|}{ Model Performance } \\
& RMSE & EF & ND \\
\hline $\mathrm{GDD}_{\mathrm{t}}$ & 57.49 & -0.06 & 0.00 \\
$\mathrm{GDD}_{\mathrm{t}} \times \mathrm{SFP}$ & 48.95 & 0.23 & 0.00 \\
$\mathrm{GDD}_{\mathrm{t}} \times \mathrm{SFV}$ & 10.06 & 0.97 & 0.00 \\
$\mathrm{GDD}_{\mathrm{t}} \times \mathrm{SFV} \times \mathrm{SFP}$ & 7.68 & 0.98 & 0.00 \\
\hline
\end{tabular}

436

\subsection{Posterior distribution of crop parameters and model validation}

Table 4 summarizes the main descriptor of the posterior distribution function of the different parameters, namely the best parameter set, the median parameter set and its $10 \%-90 \%$ confidence interval. Table S3 presents the correlation matrix between the parameters. 


\begin{tabular}{|c|c|c|c|}
\hline Parameter & Best & Median & $\mathrm{Cl}[10 \%-90 \%]$ \\
\hline$D T_{\min }$ & 0.35 & 0.49 & {$[0.059-1.002]$} \\
\hline $\mathrm{VV}_{\text {req }}$ & 71.90 & 66.97 & [36.116 - 79.378] \\
\hline$T_{\text {vern }}$ & 4.64 & 4.49 & [2.94 - 5.387] \\
\hline Ampli $_{\text {vern }}$ & 7.43 & 7.09 & [5.296 - 8.452] \\
\hline PhotoP $_{\text {base }}$ & 9.65 & 9.99 & [9.369 - 10.821] \\
\hline PhotoP $_{\text {sat }}$ & 17.90 & 17.33 & [15.687 - 22.336] \\
\hline$\Sigma \mathrm{UPVT}_{\mathrm{BBCH}}$ & 212.26 & 191.26 & [127.534 - 260.885] \\
\hline$\Sigma U{ }^{\prime}$ & 392.14 & 413.15 & [282.854 - 537.153] \\
\hline$\Sigma U{ }^{\prime}$ & 859.03 & 877.51 & [601.251 - 1112.863] \\
\hline$\Sigma \mathrm{UPVT}_{\mathrm{BBCH} 89}$ & 1585.56 & 1622.31 & [1354.823 - 1865.226] \\
\hline
\end{tabular}

446 Among the parameters optimized, $\mathrm{DT}_{\min }$ tends towards " 0 " indicating that no growth is achieved

447 below this value, as found in other crops and grasses. $T_{\text {vern }}$ indicates the optimal vernalization 448 temperature is reached around $4.6^{\circ} \mathrm{C}$, which tends to be similar or lower than other temperate

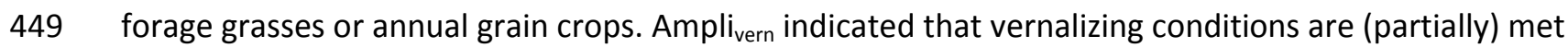
450 between $\sim-2.8$ and $\sim+12^{\circ} \mathrm{C}$. The total cold requirements $\left(\mathrm{V}_{\text {req }}\right)$ were found to be equal to 58 days, 451 which would be a more grass-like type (Table S1), since most annual grain crops are capable of 452 vernalization with shorter cold periods. However, it is worth mentioning that some annual cultivars 453 of winter wheat might require a similar amount of vernalizing days (Gate, 1995). Finally, we found 454 that photoperiod was unlocked starting at 9.7 hours and would not be limiting anymore over 17.9 455 hours of daylength. This daylength range implies that the SFP formalism takes a value of 0.5 around $45611.8 \mathrm{~h}$ daylength, and 1 at $13.8 \mathrm{~h}$ daylength. Overall, the optimized parameters confirm the relevance 457 of a temperature-daylength coupled formalism to represent IWG phenological development under 458 various growing conditions.

459 The correlation matrix (Table S3) indicates the level of correlation between parameters during the optimization process. A strong interdependency is observed between the sums of UPVT, which are also strongly correlated to $\mathrm{PhotoP}_{\text {sat }}$. The limited contrast on upper photoperiod values in the dataset 
generates uncertainty on the parameter Photo $\mathrm{P}_{\text {sat, }}$, that leads to lower reliability on the different

463 ¿UPVT due to the high correlation of both parameters. This might be solved by integrating new

464 observations gathered at Northern sites (e.g. Sweden), to precisely determine the saturation upper

465 limit of the photoperiod effect.

466 The model exhibited high performance both under calibration and validation datasets (Fig. 1 and

467 Table 5). The RMSE were respectively of 7.7 and 7.8 days, which respectively corresponded to a $2.4 \%$

468 and 2.5\% RRMSE (RMSE relative to the average of respective observations) in both cases. Model

469 efficiencies were close to 1 , which is the upper theoretical threshold, indicative of a near perfect fit

470 of the model against observations. Finally, the normalized deviations, which indicate the tendency to

471 over- or underestimate observations, were very close to " 0 " and far below the 0.1 acceptance

472 threshold. As can be seen in Fig. 3, the simulated phenology (DAE/DAH at which the stage is

473 supposed to occur) is almost perfectly aligned on the 1:1 line with the observed phenology.

474 Table 5: Model performances under the calibration and validation steps

\begin{tabular}{|lll|}
\hline Criteria & Calibration & Validation \\
\hline RMSE & 7.562 & 8.401 \\
EF & 0.982 & 0.978 \\
ND & -0.001 & 0.010 \\
\hline
\end{tabular}

475

476 


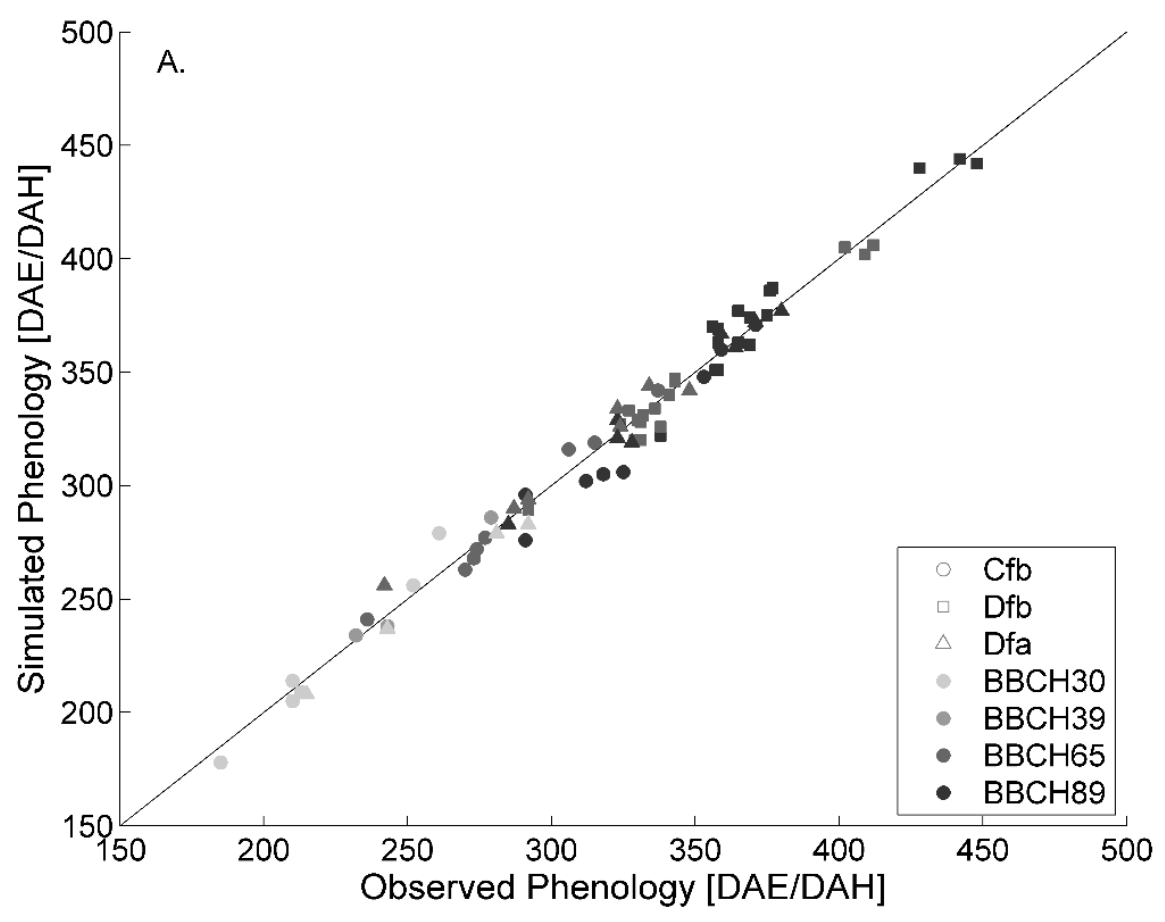

477

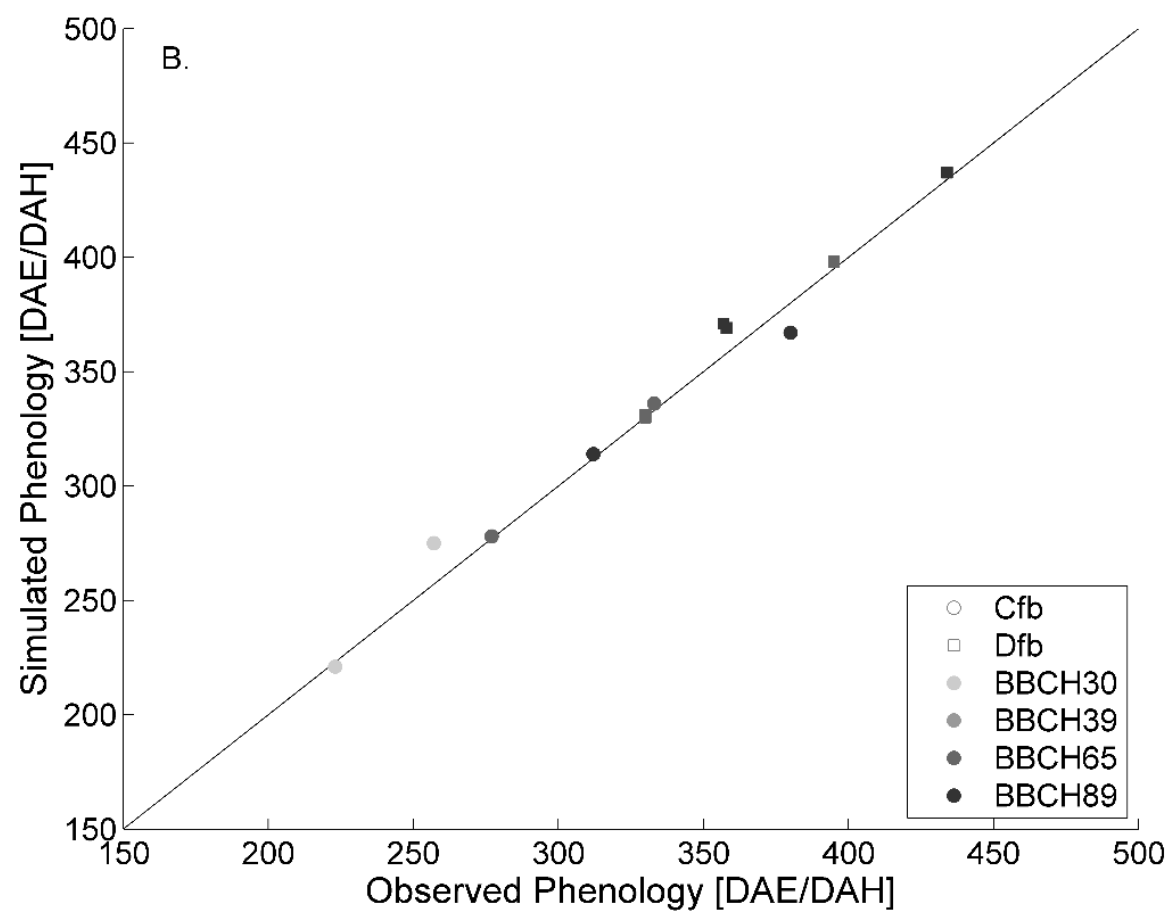

478

479 Figure 1: Observed and simulated phenology for the calibration (A) and validation (B) datasets. Climate type Cfb is 480 represented by circles (o), climate type Dfb is represented by squares ( $\square$ ) and climate type Dfa is represented by triangle

$481(\Delta)$. Intensity of grey varies with simulated crop stage in BBCH scale, with lighter grey being stem extension (BBCH 30$)$ and

482 darker grey being maturity (BBCH 89). 

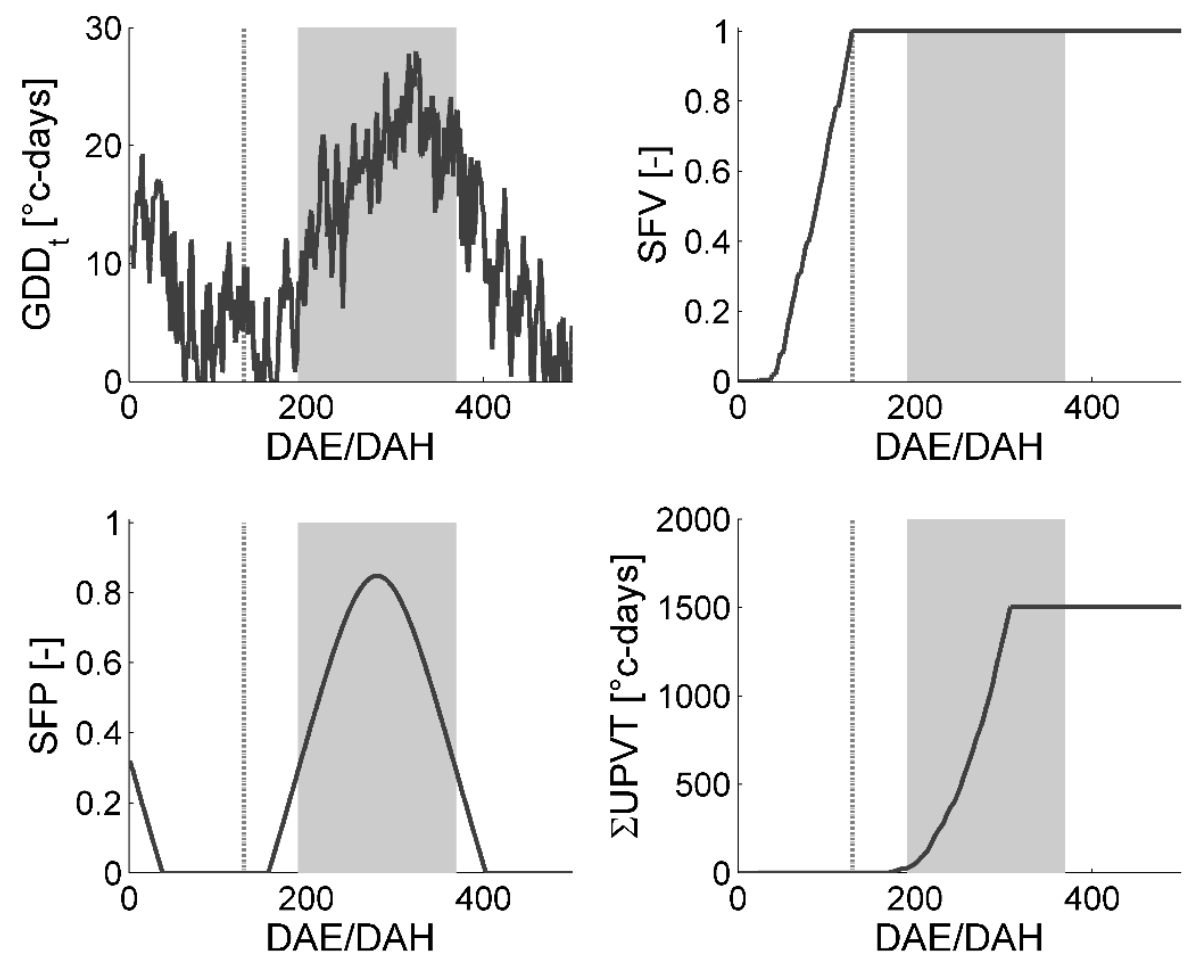

485

486 Figure 2: Simulated $\mathrm{GDD}_{\mathrm{t}}$ (Growing-Degree-Day), SFV (Slowdown Factor accounting for Vernalization), SFP (Slowdown

Factor accounting for Photoperiod) and UPVT (Photo-Vernalo-Thermic Units) for the Maubec French site (validation site)

488 over the season 2018 (establishment year). Light grey dashed line represents the day where cold requirement is fully met. Light grey shaded area represents the period for which SFP is greater than 0.3 ( $>11$ h daylength). UPVT accumulation was stopped when maturity was reached. 

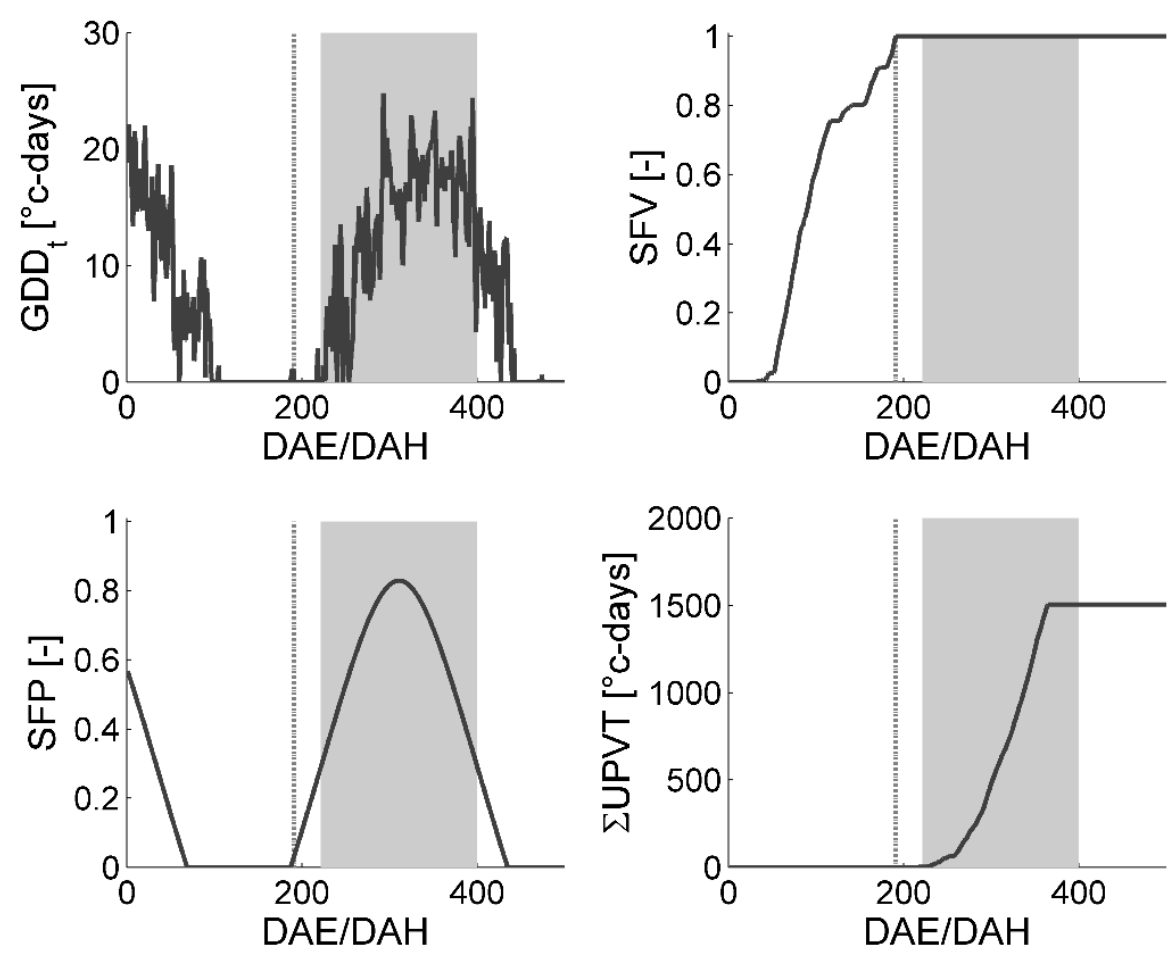

491

492 Figure 3: Simulated $\mathrm{GDD}_{\mathrm{t}}$ (Growing-Degree-Day), SFV (Slowdown Factor accounting for Vernalization), SFP (Slowdown

493 Factor accounting for Photoperiod) and UPVT (Photo-Vernalo-Thermic Units) for the Carman-LN Canadian site (validation

494 site) over the season 2017 (second growing year). Light grey dashed line represent the day where cold requirement is fully met. Light grey shaded area represent period for which SFP is greater than 0.3 (>11h daylength). UPVT accumulation was stopped when maturity was reached. 

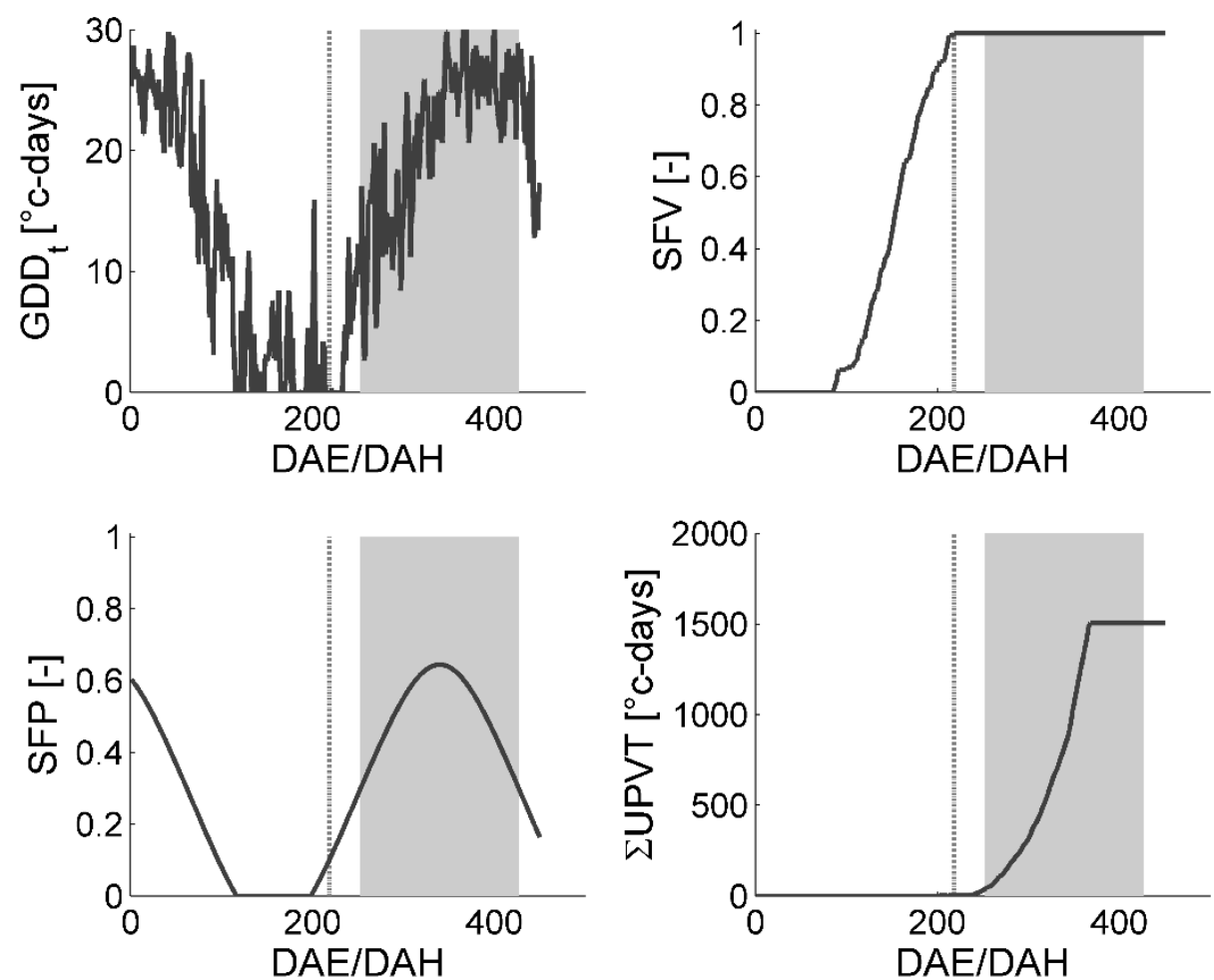

497

498

499

500

501

502

503

504

505

506

507

508

509

510

511

Figure 4: Simulated $\mathrm{GDD}_{\mathrm{t}}$ (Growing-Degree-Day), SFV (Slowdown Factor accounting for Vernalization), SFP (Slowdown Factor accounting for Photoperiod) and UPVT (Photo-Vernalo-Thermic Units) for the Salina US site (calibration site) over the season 2017 (second growing year). Light grey dashed line represents the day where cold requirements is fully met. Light grey shaded area represents the period for which SFP is greater than 0.3 ( $>11$ h daylength). UPVT accumulation was stopped when maturity was reached.

Comparing the two validation sites (Maubec-18: Cfb climate, and Carman-LN-17: Dfb climate) and one calibration site (Salina: Dfa climate), the dynamic of UPVT accumulation is expressing the combined status of the SFV, SFP and GDD parameters. The period of UPVT accumulation between sites indicates the development of reproductive growth of Th. intermedium, which correspond to the progression from $\mathrm{BBCH} 30$ to $\mathrm{BBCH} 89$ stages.

- Under Cfb climate (temperate European conditions, e.g. Maubec-18, Fig. 2), fulfillment of vernalization requirements was reached in early January ( $\sim 40 \mathrm{DAE})$ after around 90 days of SFV accumulation. However, UPVT accumulation encompasses a period of about 110 days corresponding to the period between March and July. Despite early GDD accumulation, the 

UPVT accumulation. This would represent a period of about two months between vernalization achievement and significant reproductive growth, which means early development and secondary induction of Th. intermedium was limited by the photoperiod mediation and short daylength.

- Under Dfb climate (Canadian conditions, e.g. Carman-LN-17, Fig. 3), fulfillment of vernalization requirements was reached in March ( $\sim 190 \mathrm{DAH})$ after around 140 days of SFV accumulation. UPVT accumulation encompasses a period of about 150 days corresponding to the period between April and September. This start of reproductive growth corresponds to both the start of GDD accumulation and the increased daylength ( $>11 \mathrm{~h}$, grey zones in the figure 6.) In other words, Th. intermedium early development (prior to April) would have been limited by both GDD and short daylength, indicating a notable temperature-daylength coupling.

- Under Dfa climate (continental US conditions, e.g. Salina-19, Fig. 4): fulfillment of vernalization requirements was also reached in March ( 210 DAH) after around 120 days of SFV accumulation. UPVT accumulation encompasses a period of about 130 days corresponding to the period between April and July. The start of reproductive growth corresponds to the increased daylength ( $>11 \mathrm{~h}$, grey zones in Fig 7.), while GDD was never the limiting factor. In other words, Th. intermedium early development would have been mostly limited by short daylengths.

\section{Discussion}

\subsection{Tiller primordia induction (primary induction)}

Th. intermedium appears to be highly dependent on the vernalizing process. The requirements for low temperatures (LT) is almost mandatory for tiller induction, but our study was not calibrated to uncover the potential influence of contrasted daylength (SD-LD) on these requirements. With 
vernalizing temperatures between -2.8 and $12{ }^{\circ} \mathrm{C}$ (optimum at $4.6^{\circ} \mathrm{C}$; in keeping with Ivancic et al., under review ; Table 4), LT requirements are similar to winter cereal grain crops and other vernalizing cool-season grasses (Lolium perenne, Festuca pratensis, Poa pratensis, Agrostis capillaris) (Table S1), although certain species would have greater vernalizing success than IWG under cooler temperatures (e.g. Dactylis glomerata, Bromus inermis), shorter periods of exposure (annual grains), or longer periods of exposure (other perennial grasses). Depending on climatic conditions, earliness of vernalization fulfillment might differ significantly and substantially influence dormancy break. Considering the large and general trend where LD increase LT requirements (if not inhibiting) in various vernalizing grasses, we can hypothesize that Th. intermedium would behave similarly (Heide, 1987, 1984) and might require an increased vernalization treatment under longer daylengths.

Interestingly, no significant discrepancy was observed at the sward level in the phenology model between the different germplasm origins (TLI, UMN) and breeding cycles tested (TLI-C3, C4, C5). Among the populations considered, it is notable that the Canadian sites grew experimental populations that were de facto selected for increased winter survival capacity (Cattani, 2017; Cattani and Asselin, 2018b). Therefore, their similar fitness with respect to the phenology model indicates that either: i) cold tolerance of Th. intermedium may not be tightly linked to the vernalization process (Seppänen et al., 2013); and/or ii) differences in vernalizing requirements were too subtle to be detected; and/or iii) the integration of winter snow-cover into the model, and the induced air temperature corrections, masks a potential discrepancy.

\subsection{Tiller growth and flowering (secondary induction)}

Following vernalization achievement, the accumulation of heat units (GDD base 0 ; Table 4) that triggers break of dormancy, plant growth and flowering were strongly associated with a photoperiodmediated process (Fig. 5). Such daylength induction confirms that primary induction must be followed by a secondary induction - including daylength responsiveness - that starts the reproductive 
growth period (stem elongation and flowering). Across all sites and years, initiation of anthesis was

565 observed between June 14 and July 2. In spite of the contrasted growing conditions and accumulated

566 GDD reported in Table 2, this relatively synchronized flowering period, would confirm the influence of photoperiod regulation on growth rate and demonstrate the misrepresentation of GDD concept alone to explain Th. intermedium phenological development in the various growing regions. Such a photoperiod mediation process is widely known and observed in forage grasses and cereal grains, but the degree of sensitivity varies. The proposed phenological model indicates the potential for reproductive growth between 9.7 and $17.9 \mathrm{~h}$ daylength (Table 4), but we noted that new observations on Northern regions would likely lower the saturation upper limit of the photoperiod

573 effect. According to the demonstration of UPVT accumulation (Fig 2, 3, 4), plant phenological 574 development from $\mathrm{BBCH} 30$ generally began around $11 \mathrm{~h}$ of daylength. Earlier development was 575 however possible with temperatures above $0^{\circ} \mathrm{C}$, but was strongly limited due to the combination of 576 low GDD and SFPI coefficient $<0.3$, or may have resulted in vegetative growth rather than 577 reproductive tiller development. Between 13 and $14 \mathrm{~h}$ daylengths, plant development was not 578 limited by the photoperiodic response and was fully associated with GDD accumulation. 


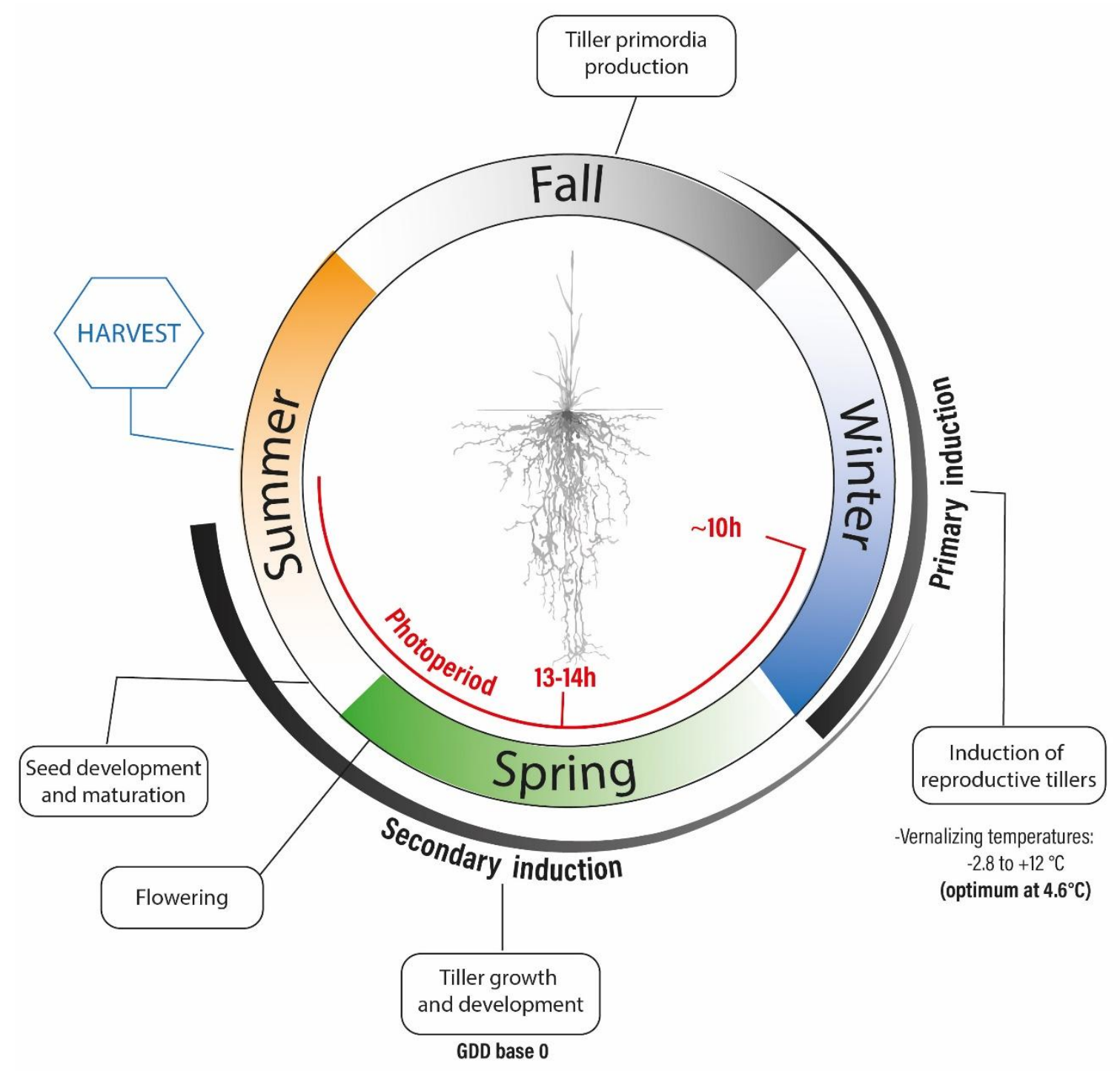

Figure 5: Thinopyrum intermedium phenological development milestones and environmental drivers. (with colors)

\subsection{Tiller elongation: a crucial context-dependent trait to manage production}

In production fields, flowering earliness is a critical factor since it provides a good representation of the whole growth cycle timing and stages (Ansquer et al., 2009a), driving the field operations agenda (e.g. fertilization). In spite of the variability of flowering earliness due to different growth rates and stem elongation, particularly influenced by $\mathrm{N}$ availability, the calculation of GDD under similar climatic and daylength contexts has been demonstrated as a robust method to predict flowering periods of different cool-season forage grasses (Ansquer et al., 2009a). Therefore, it has been 
accepted as one of the main criteria that distinguish different plant growth strategies under similar situations and low-input systems (Ansquer et al., 2009a; Cruz et al., 2010; Duru et al., 2009).

Under French and Belgium temperate conditions, GDD calculation until flowering (Table 2) indicate that Th. intermedium belongs to the slow-growing and more 'conservative' plants commonly found in these regions (e.g. Brachypodium sp., Agropyron sp., Deschampsia cespitosa, Phleum pratense) compared to earlier plants (e.g. Alopecurus pratense, Lolium perenne, Festuca pratense). These later flowering species are generally characterized by taller stands, longer leaf lifespan, lower leaf area per mass unit, lower leaf nitrogen concentration and relative growth rate (Ansquer et al., 2009b; Cruz et al., 2010; Duru et al., 2005, 1995; Ryser and Lambers, 1995). In low input fields, slow establishment and a slow growing canopy can result in weed infestations and poor grain filling in dry conditions in late summer. As a result, slow-growing species like IWG may be better suited to higher altitude fields or higher latitude situations often characterized by delayed growth season.

On the other hand, the Th. intermedium flowering period in the North American continental context might be seen as relatively early (lower GDD accumulation) compared to warm-season grasses Panicum virgatum, Andropogon gerardii and Sorghastrum nutans commonly found under harsh growing conditions of the Northern Great Plains Tallgrass Prairie. Those species are described as very conservative, capable of high biomass production and very efficient in nitrogen recycling and use (Friesen and Cattani, 2017). Conversely, Th. intermedium would require higher nitrogen concentration and require more nitrogen availability to ensure optimal reproductive growth under similar conditions. Compared to warm-season grasses, the more acquisitive traits of Th. intermedium would be favorable to quicker plant growth and establishment in fields in situations of suitable resource availability. 

to the loss of cold hardiness in the spring could be the difference in observed response between Western Europe and the Northern Great Plains of North America and its continental climate. If a plant loses its cold acclimation and the plant has yet to reach the inductive day length (or gdd accumulation combination), nutrients and water may be used for new vegetative tiller recruitment. Internode elongation will be both energy and water demanding. When induction conditions are met, nutrients (including water) may be diverted from reproductive growth to support excessive vegetative growth, reducing seed yield. Thus, timing of secondary induction and spring regrowth will be critical to optimizing the response to fertilization. For instance, if dormancy is broken and growth begins potentially in February (in France) and the flowering response is primarily to longer days (>13hr daylength), the pre-reproductive growth will be much longer duration than in Manitoba, Canada, where cold tolerance and dormancy will still be intact at that time of year. Therefore, growth 627 will appear to be quicker in Manitoba as less time, if any, elapses between the resumption of growth 628 in the spring and the onset of reproductive growth.

629 Under situations with prolonged non-reproductive growth after winter time, as observed in western 630 European conditions, the ability of other species to respond to early fertility boost and grow reproductively may provide an advantage to weed species, e.g. perennial ryegrass (Lolium perenne). Selection for earlier flowering in these growth environments, potentially achieved though different and possibly interrelated methods (e.g. reducing phyllochron through reduced leaf length and appearance rate, or by altering daylength requirements) would then alter this timing relationship, and should move anthesis earlier in the growing season and potentially reduce the stressful influences from a later secondary induction timing. Extreme heat during anthesis, as experienced in reduced grain yields of this new perennial crop. 
The flowering induction process is critical to understanding environmental requirements that support Th. intermedium reproductive growth, however it is primarily relevant when linked to flowering and reproductive growth rate traits within a specific growth situation. The understanding of the phenology will therefore inform agronomic practices.

\subsection{Scaling up the use of Th. intermedium grain production by designing and pairing} ecotypes with geographies for optimized flowering induction

Model compliance is based on IWG overall sward growth, without taking inter- and intra-individual heterogeneity into account. However, individual discrepancy in flowering period has been observed within fields. The observation of slower tillers, with delayed heading and flowering, calls for further research on axillary bud production and induction, linked to vegetative growth periods and resource availability dynamics. Also, with spring seedings, flowering in summer has been observed without previous winter vernalization, although seed harvest would not be profitable due to the timing and the limited amount of flowering observed. Such heterogeneity is regularly observed in perennial grasses, and might indicate a potential breeding opportunity to develop ideotypes with favorable phenology for specific target populations of environments. In the meantime, the effect of reducing population diversity must be taken into account in order to define appropriate thresholds that maintain the benefits of population diversity in fields (e.g. resilience, longevity). Breeding for a more uniform ideotype may alter plant growth and might expose the crop to other issues not historically associated with the species. For example, greater Th. intermedium earliness in breaking in dormancy in the spring carries the risk of injury under later occurring adverse climatic conditions or seed productivity decline (Cattani, 2017). Likewise, breeding toward more acquisitive plant traits associated with quicker growth may also bring new drawbacks such as increased disease problems (increased leaf moisture), reduced longevity or increased susceptibility to drought. More conservative plants typically have higher water use efficiency (De Oliveira et al., 2019, 2018), while acquisitive plants utilize water quickly to grow rapidly. 
Influence of management practices such as fertilization illustrates the plasticity of acquisitive-

667

668

669

670

671

672

673

674

675

676

677

678

679

680

681

682

683

684

685

686

687

688

689

690

691

conservative plant functional types in managed growth environments, which potentially can be very different in terms of resource availability, competitive interactions and climatic effects as compared to the native growth habitat of the plant. Among the most studied practices, nitrogen fertilization of forage grasses, was shown to be responsible for improving leaf elongation rate and leaf area (Gastal and Durand, 2000) thus potentially impacting the overall plant growth rate, assimilation, and tillering (Mitchell et al., 1998; Poorter and Remkes, 1990; Shipley, 2006; Simon and Lemaire, 1987). Similarly, the management of defoliation practices might widely influence plant growth, notably due to influence on carbon and nitrogen fluxes and reserves (Ferraro and Oesterheld, 2002; Gastal et al., 2010; Gastal and Lemaire, 2015; Hunter et al., 2020; Medina-Roldán and Bardgett, 2011). The usually large ontogenic plasticity of forage grasses also reinforces the influence of defoliation, which result in disturbed phytomers. According to Nelson (2000), most cool-season grasses demonstrate interrelated vegetative (leaf) growth and tillering, whereas vegetative growth improvement (biomass) generally reduces tillering and lengthens the phyllochron, likely due to increased light interception and competition to the detriment of axillary (tiller) bud activation (Simon and Lemaire, 1987). Thus, significant non-reproductive growth under favorable environmental conditions might ultimately lead to fewer tillers. This would be similar to observed situations under aging (three-four years old), or "sod-bound" Th. intermedium stands, where tillering activity is strongly reduced (Hunter et al., 2020; Tautges et al., 2018), and may require strategic canopy disturbance to maintain reproductive tillers. Thus, a large field of research remains open to determine the interactions between agronomic management and directed breeding, with plant plasticity, including reproductive growth rate, timing and intensity, to optimize its reproductive potential.

\section{Conclusion}

This study shows that introducing a new grain crops from new genotype and ecotype pools requires a broader assessment than only attention towards its yield potential. Here we show that vernalization, followed by GDD-daylength coupled dynamics in spring, drives IWG sward functional changes, 
cropping system management. Our results highlight the need to develop an integrative research

approach combining crop genetics, ecology and agronomy to improve our understanding of our cropping systems as a whole.

696

697

698

699

700

701

702

703

704

705

706

707

708

709

710

711

712

713

714

715

716

717

718

719

720

721

722

723

724

\section{Acknowledgement}

We acknowledge all field technicians and scientists that contributed to create and assemble this dataset. We also thank the reviewers for their usefull comments.

\section{References}

Aamlid, T., 2000. Primary and Secondary Induction Requirements for Flowering of Contrasting European Varieties of Lolium perenne. Annals of Botany 86, 1087-1095. https://doi.org/10.1006/anbo.2000.1275

Ansquer, P, Duru, M., Theau, J.P., Cruz, P., 2009. Functional traits as indicators of fodder provision over a short time scale in species-rich grasslands. Ann Bot 103, 117-126. https://doi.org/10.1093/aob/mcn215

Ansquer, P., Khaled, R.A.H., Cruz, P., Theau, J.-P., Therond, O., Duru, M., 2009. Characterizing and predicting plant phenology in species-rich grasslands. Grass and Forage Science 64, 57-70. https://doi.org/10.1111/j.1365-2494.2008.00670.x

Ansquer, P., Theau, J.-P., Cruz, P., Viegas, J., Al Haj Khaled, R., Duru, M., 2004. Caracterisation de la diversité fonctionnelle des prairies à flore complexe. Vers la construction d'outils de gestion. Fourrages 179, 353-368

Bajgain, P., Zhang, X., Jungers, J.M., DeHaan, L.R., Heim, B., Sheaffer, C.C., Wyse, D.L., Anderson, J.A., 2020. 'MN-Clearwater', the first food-grade intermediate wheatgrass (Kernza perennial grain) cultivar. J. Plant Regist. 14, 288-297. https://doi.org/10.1002/plr2.20042

Bartholomew, P.W., Williams, R.D., 2005. Cool-Season Grass Development Response to Accumulated Temperature under a Range of Temperature Regimes. Crop Sci. 45, 529-534. https://doi.org/10.2135/cropsci2005.0529

Basu, S., Parya, M., Dutta, S.K., Jena, S., Maji, S., Nath, R., Mazumdar, D., Chakraborty, P.K., 2012. Effect of growing degree day on different growth processes of wheat (Triticum aestivum L.). Journal of Crop and Weed, 8, 18-22.

Beaudoin, N., Launay, M., Sauboua, E., Ponsardin, G., Mary, B., 2008. Evaluation of the soil crop model STICS over 8 years against the "on farm" database of Bruyères catchment. European Journal of Agronomy 29, 46-57. https://doi.org/10.1016/j.eja.2008.03.001

Brisson, N., Delecolle, R., 1992. Developpement et modeles de simulation de cultures. Agronomie 12, 253-263.

Brisson, N., Launay, M., Mary, B. (Eds.), 2009. Conceptual basis, formalisations and parameterization of the STICS crop model, Quae. ed, Update Sciences and technologies.

Brisson, N., Mary, B., Ripoche, D., Jeuffroy, M.H., Ruget, F., Nicoullaud, B., Gate, P., Devienne-Barret, F., Antonioletti, R., Durr, C., Richard, G., Beaudoin, N., Recous, S., Tayot, X., Plenet, D., Cellier, P., Machet, J.-M., Meynard, J.M., Delécolle, R., 1998. STICS: a generic model for the simulation of crops and their water and nitrogen balances. I. Theory and parameterization applied to wheat and corn. Agronomie 18, 311-346. https://doi.org/10.1051/agro:19980501 
Brisson, N., Ruget, F., Gate, P., Lorgeou, J., Nicoullaud, B., Tayot, X., Plenet, D., Jeuffroy, M.-H., Bouthier, A., Ripoche, D., Mary, B., Justes, E., 2002. STICS: a generic model for simulating crops and their water and nitrogen balances. II. Model validation for wheat and maize. Agronomie 22, 69-92. https://doi.org/10.1051/agro:2001005

Brown, W.F., Moser, L.E., Klopfenstein, T.J., 1986. Development and validation of a dynamic model of growth and quality for cool season grasses. Agricultural Systems 20, 37-52. https://doi.org/10.1016/0308-521X(86)90034-X

Casler, M.D., 2012. Switchgrass Breeding, Genetics, and Genomics, in: Monti, A. (Ed.), Switchgrass, Green Energy and Technology. Springer London, London, pp. 29-53. https://doi.org/10.1007/978-1-4471-2903-5_2

Castro, J.C., Boe, A., Lee, D.K., 2011. A Simple System for Promoting Flowering of Upland Switchgrass in the Greenhouse. Crop Science 51, 2607-2614. https://doi.org/10.2135/cropsci2011.03.0142

Cattani, D., 2017. Selection of a perennial grain for seed productivity across years: Intermediate wheatgrass as a test species. Canadian Journal of Plant Science 97. https://doi.org/10.1139/CJPS-2016-0280

Cattani, Douglas, Asselin, S.R., 2018a. Has Selection for Grain Yield Altered Intermediate Wheatgrass? Sustainability 10, 688. https://doi.org/10.3390/su10030688

Cattani, Doug, Asselin, S.R., 2018b. Extending the Growing Season: Forage Seed Production and Perennial Grains. Can. J. Plant Sci. 98, 235-246. https://doi.org/10.1139/CJPS-2017-0212

Chauvel, B., Munier-Jolain, N., Letouzé, A., Grandgirard, D., 2000. Developmental patterns of leaves and tillers in a black-grass population (Alopecurus myosuroides Huds.). Agronomie 20, 247-257. https://doi.org/10.1051/agro:2000124

Chauvel, B., Munier-Jolain, N.M., Grandgirard, D., Gueritaine, G., 2002. Effect of vernalization on the development and growth of Alopecurus myosuroides. Weed Research 42, 166-175. https://doi.org/10.1046/j.1365-3180.2002.00276.x

Chouard, P., 1960. Vernalization and its Relations to Dormancy. Annual Review of Plant Physiology 11, 191-238. https://doi.org/10.1146/annurev.pp.11.060160.001203

Cooper, J.P., Calder, D.M., 1964. The Inductive Requirements for Flowering of Some Temperate Grasses. Grass and Forage Science 19, 6-14. https://doi.org/10.1111/j.13652494.1964.tb01133.x

Crews, T.E., 2016. Closing the Gap between Grasslands and Grain Agriculture. Kan. JL \& Pub. Pol'y 26, 274.

Cruz, P., Theau, J.P., Lecloux, E., Jouany, C., Duru, M., 2010. Typologie fonctionnelle de graminées fourragères pérennes: une classification multitraits. Fourrages 201, 11-17.

Davidson, J.L., Milthorpe, F.L., 1965. The Effect of Temperature on the Growth of Cocksfoot (Dactylis glomerata L.). Ann Bot 29, 407-417. https://doi.org/10.1093/oxfordjournals.aob.a083962

De Oliveira, G., Brunsell, N.A., Crews, T.E., DeHaan, L.R., Vico, G., 2019. Carbon and water relations in perennial Kernza (Thinopyrum intermedium): An overview. Plant Science 110279-. https://doi.org/10.1016/j.plantsci.2019.110279

De Oliveira, G., Brunsell, N.A., Sutherlin, C.E., Crews, T.E., DeHaan, L.R., 2018. Energy, water and carbon exchange over a perennial Kernza wheatgrass crop. Agricultural and Forest Meteorology 249, 120-137. https://doi.org/10.1016/j.agrformet.2017.11.022

DeHaan, L., 2015. Perennial crops are a key to sustainably productive agriculture, in: Food Security : Production and Sustainability.

DeHaan, L., Christians, M., Crain, J., Poland, J., 2018. Development and Evolution of an Intermediate $\begin{array}{lllll}\text { Wheatgrass Domestication Program. Sustainability } & 10,\end{array}$ https://doi.org/10.3390/su10051499

Dubcovsky, J., Loukoianov, A., Fu, D., Valarik, M., Sanchez, A., Yan, L., 2006. Effect of Photoperiod on the Regulation of Wheat Vernalization Genes VRN1 and VRN2. Plant Mol Biol 60, 469-480. https://doi.org/10.1007/s11103-005-4814-2 
Duchene, O., Celette, F., Ryan, M.R., DeHaan, L.R., Crews, T.E., David, C., 2019. Integrating multipurpose perennial grains crops in Western European farming systems. Agriculture, Ecosystems \& Environment 284, 106591. https://doi.org/10.1016/j.agee.2019.106591

Dumont, B., Leemans, V., Mansouri, M., Bodson, B., Destain, J.-P., Destain, M.-F., 2014. Parameter identification of the STICS crop model, using an accelerated formal MCMC approach. $\begin{array}{lllll}\text { Environmental } \quad \text { Modelling } & \text { Software } & \text { 52, }\end{array}$ https://doi.org/10.1016/j.envsoft.2013.10.022

Durand, R., 1967. Action de la température et du rayonnement sur la croissance. Ann. Physiol. Vég. 5-27.

Duru, M., Al Haj Khaled, R., Ducourtieux, C., Theau, J.P., de Quadros, F.L.F., Cruz, P., 2008a. Do plant functional types based on leaf dry matter content allow characterizing native grass species and grasslands for herbage growth pattern? Plant Ecology 201, 421-433. https://doi.org/10.1007/s11258-008-9516-9

Duru, M., Ducrocq, H., Tirilly, V., 1995. Modeling growth of cocksfoot (Dactylis glomerata L.) and tall fescue (Festuca arundinacea schreb.) at the end of spring in relation to herbage nitrogen status. Journal of Plant Nutrition 18, 2033-2047. https://doi.org/10.1080/01904169509365042

Duru, M., Justes, E., Langlet, A., Tirilly, V., Rouziès, S., Sos, L., Viard, R., 1993. Comparaison des dynamiques d'apparition et de mortalité des organes de fétuque élevée, dactyle et luzerne (feuilles, talles et tiges). Agronomie 13, 237-252. https://doi.org/10.1051/agro:19930401

Duru, M., Adam, M., Cruz, P., Martin, G., Ansquer, P., Ducourtieux, C., Jouany, C., Theau, J.P., Viegas, J., 2008c. Modelling above-ground herbage mass for a wide range of grassland community types. Ecol. Model. 220, 209-225. https://doi.org/10.1016/j.ecolmodel.2008.09.015

Duru, M., P, P.C., Raouda, A.H.K., Ducourtieux, C., Theau, J.P., 2008b. Relevance of Plant Functional Types based on Leaf Dry Matter Content for Assessing Digestibility of Native Grass Species and Species-Rich Grassland Communities in Spring. Agronomy Journal 100, 1622-1630. https://doi.org/10.2134/agronj2008.0003

Duru, M., Tallowin, J., Cruz, P., 2005. Functional diversity in low input grassland farming systems: characterisation, effect and management, in: Integrating Efficient Grassland Farming and Biodiversity. Tartu, pp. 199-210.

Esbroeck, G.A.V., Hussey, M.A., Sanderson, M.A., 2003. Variation between Alamo and Cave-in-Rock Switchgrass in Response to Photoperiod Extension. Crop Science 43, 639-643. https://doi.org/10.2135/cropsci2003.6390

Esbroeck, G.A.V., Hussey, M.A., Sanderson, M.A., 1997. Leaf Appearance Rate and Final Leaf Number of Switchgrass Cultivars. Crop Science 37, 864-870. https://doi.org/10.2135/cropsci1997.0011183X003700030028x

Ferraro, D.O., Oesterheld, M., 2002. Effect of defoliation on grass growth. A quantitative review. Oikos 98, 125-133. https://doi.org/10.1034/j.1600-0706.2002.980113.x

Fowler, D.B., Limin, A.E., Wang, S.-Y., Ward, R.W., 1996. Relationship between low-temperature tolerance and vernalization response in wheat and rye. Canadian Journal of Plant Science 76, 37-42. https://doi.org/10.4141/cjps96-007

Frank, A.B., Bauer, A., 1995. Phyllochron Differences in Wheat, Barley, and Forage Grasses. Crop Science 35, 19-23. https://doi.org/10.2135/cropsci1995.0011183X003500010004x

Frank, A.B., Hofmann, L., 1989. Relationship among Grazing Management, Growing Degree-Days, and Morphological Development for Native Grasses on the Northern Great Plains. J. Range Manag. 42, 199. https://doi.org/10.2307/3899472

Friesen, P.C., Cattani, D.J., 2017. Nitrogen use efficiency and productivity of first year switchgrass and big bluestem from low to high soil nitrogen. Biomass and Bioenergy 107, 317-325. https://doi.org/10.1016/j.biombioe.2017.10.016

Frischknecht, N.C., 1959. Effects of Presowing Vernalization on Survival and Development of Several Grasses. J. Range Manag. 12, 280. https://doi.org/10.2307/3894972

Gall, H.J.F., 1947. Flowering of Smooth Brome Grass Under Certain Environmental Conditions. Botanical Gazette 109, 59-71. https://doi.org/10.1086/335456 
Gastal, F., Dawson, L.A., Thornton, B., 2010. Responses of plant traits of four grasses from contrasting habitats to defoliation and $\mathrm{N}$ supply. Nutr Cycl Agroecosyst 88, 245-258. https://doi.org/10.1007/s10705-010-9352-x

Gastal, F., Durand, J.-L., 2000. Effects of nitrogen and water supply on $\mathrm{N}$ and $\mathrm{C}$ fluxes and partitioning in defoliated swards, in: Grassland Ecophysiology and Grazing Ecology. pp. 15-39.

Gastal, F., Lemaire, G., 2015. Defoliation, Shoot Plasticity, Sward Structure and Herbage Utilization in Pasture: Review of the Underlying Ecophysiological Processes. Agriculture 5, 1146-1171. https://doi.org/10.3390/agriculture5041146

Gate, P., 1995. Ecophysiologie du blé. Tec \& Doc-Lavoisier.

Glover, J.D., Reganold, J.P., Bell, L.W., Borevitz, J., Brummer, E.C., Buckler, E.S., Cox, C.M., Cox, T.S., Crews, T.E., Culman, S.W., DeHaan, L.R., Eriksson, D., Gill, B.S., Holland, J., Hu, F., Hulke, B.S., Ibrahim, A.M.H., Jackson, W., Jones, S.S., Murray, S.C., Paterson, A.H., Ploschuk, E., Sacks, E.J., Snapp, S., Tao, D., Tassel, D.L.V., Wade, L.J., Wyse, D.L., Xu, Y., 2010. Increased Food and Ecosystem Security via Perennial Grains. Science 328, 1638-1639. https://doi.org/10.1126/science.1188761

Halevy, A.H., 1989. Handbook of Flowering. CRC Press.

Hänsel, H., 1953. Vernalisation of Winter Rye by Negative Temperatures and the Influence of Vernalisation upon the Lamina Length of the First and Second Leaf in Winter Rye, Spring Barley, and Winter Barley. Ann Bot 17, 417-432. https://doi.org/10.1093/oxfordjournals.aob.a083360

Hastings, W.K., 1970. Monte Carlo sampling methods using Markov chains and their applications. Biometrika 57, 97-109. https://doi.org/10.1093/biomet/57.1.97

Heide, O.M., 1994. Control of flowering and reproduction in temperate grasses. New Phytologist 128, 347-362. https://doi.org/10.1111/j.1469-8137.1994.tb04019.x

Heide, O.M., 1987. Photoperiodic control of flowering in Dactylis glomerata, a true short-long-day plant. Physiologia Plantarum 70, 523-529. https://doi.org/10.1111/j.1399-3054.1987.tb02853.x

Heide, O.M., 1986. Primary and secondary induction requirements for flowering in Alopecurus pratensis. Physiologia Plantarum 66, 251-256. https://doi.org/10.1111/j.13993054.1986.tb02416.x

Heide, O.M., 1984. Flowering requirements in Bromus inermis, a short-long-day plant. Physiologia Plantarum 62, 59-64. https://doi.org/10.1111/j.1399-3054.1984.tb05923.x

Heide, O.M., 1980. Studies on flowering in Poa pratensis L. ecotypes and cultivars. Meldinger fra Norges Landbrukshogskole 59.

Heide, O.M., Bush, M.G., Evans, L.T., 1987. Inhibitory and promotive effects of gibberellic acid on floral initiation and development in Poa pratensis and Bromus inermis. Physiologia Plantarum 69, 342-350. https://doi.org/10.1111/j.1399-3054.1987.tb04298.x

Hess, M., Barralis, G., Bleiholder, H., Buhr, L., Eggers, T., Hack, H., Stauss, R., 1997. Use of the extended $\mathrm{BBCH}$ scale-general for the descriptions of the growth stages of mono; and dicotyledonous weed species. Weed Research 37, 433-441. https://doi.org/10.1046/j.13653180.1997.d01-70.x

Hunt, W.F., Halligan, G., 1981. Growth and Developmental Responses of Perennial Ryegrass Grown at Constant Temperature. I. Influence of Light and Temperature on Growth and Net Assimilation. Functional Plant Biol. 8, 181-190. https://doi.org/10.1071/pp9810181

Hunter, M.C., Sheaffer, C.C., Culman, S.W., Jungers, J.M., 2020. Effects of defoliation and row spacing on intermediate wheatgrass i: Grain production. Agronomy Journal. https://doi.org/10.1002/agj2.20128

Ivancic, K., Locatelli, A., Tracy, B., Picasso, V., under review. Kernza intermediate wheatgrass (Thinopyrum intermedium) response to a range of vernalization conditions. Can. J. Plant Sci.

Jégo, G., Chantigny, M., Pattey, E., Bélanger, G., Rochette, P., Vanasse, A., Goyer, C., 2014. Improved snow-cover model for multi-annual simulations with the STICS crop model under cold, humid continental climates. Agricultural and Forest Meteorology 195-196, 38-51. https://doi.org/10.1016/j.agrformet.2014.05.002 
Jokela, V., Trevaskis, B., Seppänen, M.M., 2015. Genetic variation in the flowering and yield formation of timothy (Phleum pratense L.) accessions after different photoperiod and vernalization treatments. Front. Plant Sci. 6. https://doi.org/10.3389/fpls.2015.00465

Jungers, J.M., DeHaan, L.R., Betts, K.J., Sheaffer, C.C., Wyse, D.L., 2017. Intermediate Wheatgrass Grain and Forage Yield Responses to Nitrogen Fertilization. Agronomy Journal 109, 462-472. https://doi.org/10.2134/agronj2016.07.0438

Jungers, J.M., Frahm, C.S., Tautges, N.E., Ehlke, N.J., Wells, M.S., Wyse, D.L., Sheaffer, C.C., 2018. Growth, development, and biomass partitioning of the perennial grain crop Thinopyrum intermedium: Growth, development, and biomass partitioning of a perennial grain crop. Annals of Applied Biology. https://doi.org/10.1111/aab.12425

Khan, M.A., Stace, C.A., 1999. Breeding relationships in the genus Brachypodium (Poaceae: Pooideae). Nordic Journal of Botany 19, 257-269. https://doi.org/10.1111/j.17561051.1999.tb01108.x

Limin, A.E., Fowler, D.B., 2006. Low-temperature tolerance and genetic potential in wheat (Triticum aestivum L.): response to photoperiod, vernalization, and plant development. Planta 224, 360366. https://doi.org/10.1007/s00425-006-0219-y

Loague, K., Green, R.E., 1991. Statistical and graphical methods for evaluating solute transport models: Overview and application. Journal of Contaminant Hydrology, Validation of Flow and Transport Models for the Unsaturated Zone 7, 51-73. https://doi.org/10.1016/01697722(91)90038-3

Luo, Q., 2011. Temperature thresholds and crop production: a review. Climatic Change 109, 583-598. https://doi.org/10.1007/s10584-011-0028-6

Mahfoozi, S., Limin, A.E., Hayes, P.M., Hucl, P., Fowler, D.B., 2000. Influence of photoperiod response on the expression of cold hardiness in wheat and barley. Can. J. Plant Sci. 80, 721-724. https://doi.org/10.4141/P00-031

Medina-Roldán, E., Bardgett, R.D., 2011. Plant and soil responses to defoliation: a comparative study of grass species with contrasting life history strategies. Plant Soil 344, 377-388. https://doi.org/10.1007/s11104-011-0756-4

Metropolis, N., Rosenbluth, A.W., Rosenbluth, M.N., Teller, A.H., Teller, E., 1953. Equation of State Calculations by Fast Computing Machines. J. Chem. Phys. 21, 1087-1092. https://doi.org/10.1063/1.1699114

Mitchell, R.B., Moore, K.J., Moser, L.E., Fritz, J.O., Redfearn, D.D., 1997. Predicting Developmental Morphology in Switchgrass and Big Bluestem. Agronomy Journal 89, 827-832. https://doi.org/10.2134/agronj1997.00021962008900050018x

Mitchell, R.B., Moser, L.E., Moore, K.J., Redfearn, D.D., 1998. Tiller Demographics and Leaf Area Index of Four Perennial Pasture Grasses. Agronomy Journal 90, 47-53. https://doi.org/10.2134/agronj1998.00021962009000010009x

Nelson, C.J., 2000. Shoot morphological plasticity of grasses: leaf growth vs. tillering. Grassland ecophysiology and grazing ecology 101-126.

Palit, R., Bai, Y., Romo, J., Coulman, B., Pierre, R.S., 2014. Variations in vernalization requirements among ecotypes of Festuca hallii. Grass and Forage Science 70, 353-364. https://doi.org/10.1111/gfs.12101

Parthasarathi, T., Velu, G., Jeyakumar, P., 2013. Impact of Crop Heat Units on Growth and Developmental Physiology of Future Crop Production: A Review 2, 9

Peacock, J.M., 1976. Temperature and Leaf Growth in Four Grass Species. Journal of Applied Ecology 13, 225-232. https://doi.org/10.2307/2401942

Peel, M.C., Finlayson, B.L., Mcmahon, T.A., 2007. Updated world map of the Köppen-Geiger climate classification. Hydrology and Earth System Sciences Discussions 4, 439-473.

Poorter, H., Remkes, C., 1990. Leaf area ratio and net assimilation rate of 24 wild species differing in relative growth rate. Oecologia 83, 553-559. https://doi.org/10.1007/BF00317209

Porter, J.R., Gawith, M., 1999. Temperatures and the growth and development of wheat: a review. European Journal of Agronomy 10, 23-36. https://doi.org/10.1016/S1161-0301(98)00047-1 
Ritchie, J.T., 1991. Wheat Phasic Development, in: Modeling Plant and Soil Systems. John Wiley \& Sons, Ltd, pp. 31-54. https://doi.org/10.2134/agronmonogr31.c3

Ryan, M.R., Crews, T.E., Culman, S.W., DeHaan, L.R., Hayes, R.C., Jungers, J.M., Bakker, M.G., 2018. Managing for Multifunctionality in Perennial Grain Crops. BioScience 68, 294-304.

Ryser, P., Lambers, H., 1995. Root and leaf attributes accounting for the performance of fast- and slow-growing grasses at different nutrient supply. Plant Soil 170, 251-265. https://doi.org/10.1007/BF00010478

Sanderson, M.A., West, C.P., Moore, K.J., Stroup, J., Moravec, J., 1997. Comparison of Morphological Development Indexes for Switchgrass and Bermudagrass. Crop Science 37, 871-878. https://doi.org/10.2135/cropsci1997.0011183X003700030029x

Sellers, W.D., 1965. Physical climatology, University of Chicago. ed.

Seppänen, M.M., Korhonen, P., Jokela, V., Isolahti, M., Virkajärvi, P., 2013. The role of vernalization in freezing tolerance and tiller composition of forage grasses. The role of grasslands in a green future: threats and perspectives in less favoured areas. Proceedings of the 17th Symposium of the European Grassland Federation, Akureyri, Iceland, $23-26$ June 2013 297-299.

Shipley, B., 2006. Net assimilation rate, specific leaf area and leaf mass ratio: which is most closely correlated with relative growth rate? A meta-analysis. Functional Ecology 20, 565-574. https://doi.org/10.1111/j.1365-2435.2006.01135.x

Simon, J.C., Lemaire, G., 1987. Tillering and leaf area index in grasses in the vegetative phase. Grass and Forage Science 42, 373-380. https://doi.org/10.1111/j.1365-2494.1987.tb02127.x

Sprunger, C.D., Culman, S.W., Robertson, G.P., Snapp, S.S., 2018. How Does Nitrogen and Perenniality Influence Belowground Biomass and Nitrogen Use Efficiency in Small Grain Cereals? Crop Science 0, 0. https://doi.org/10.2135/cropsci2018.02.0123

Tautges, N.E., Jungers, J.M., DeHaan, L.R., Wyse, D.L., Sheaffer, C.C., 2018. Maintaining grain yields of the perennial cereal intermediate wheatgrass in monoculture $\mathrm{v}$. bi-culture with alfalfa in the Upper Midwestern USA. The Journal of Agricultural Science 1-16. https://doi.org/10.1017/S0021859618000680

Ter Braak, C.J.F., 2006. A Markov Chain Monte Carlo version of the genetic algorithm Differential Evolution: easy Bayesian computing for real parameter spaces. Stat Comput 16, 239-249. https://doi.org/10.1007/s11222-006-8769-1

Trione, E.J., Metzger, R.J., 1970. Wheat and Barley Vernalization in a Precise Temperature Gradient1. Crop Science 10, 390-392. https://doi.org/10.2135/cropsci1970.0011183X001000040023x

Vrugt, J.A., 2016. Markov chain Monte Carlo simulation using the DREAM software package: Theory, concepts, and MATLAB implementation. Environmental Modelling \& Software 75, 273-316. https://doi.org/10.1016/j.envsoft.2015.08.013

Vrugt, J.A., Gupta, H.V., Bouten, W., Sorooshian, S., 2003. A Shuffled Complex Evolution Metropolis algorithm for optimization and uncertainty assessment of hydrologic model parameters. Water Resources Research 39. https://doi.org/10.1029/2002WR001642

Vrugt J.A., ter Braak C.J.F., Diks C.G.H., Robinson B.A., Hyman J.M., Higdon D., 2009. Accelerating Markov Chain Monte Carlo Simulation by Differential Evolution with Self-Adaptive Randomized Subspace Sampling. International Journal of Nonlinear Sciences and Numerical Simulation 10, 273-290. https://doi.org/10.1515/IJNSNS.2009.10.3.273

Wallach, D., Makowski, D., Jones, J.W. (Eds.), 2006. Evaluation, analysis, parameterization and applications, in: Working with Dynamic Crop Models. Academic Press.

Wang, E., Martre, P., Zhao, Z., Ewert, F., Maiorano, A., Rötter, R.P., Kimball, B.A., Ottman, M.J., Wall, G.W., White, J.W., Reynolds, M.P., Alderman, P.D., Aggarwal, P.K., Anothai, J., Basso, B., Biernath, C., Cammarano, D., Challinor, A.J., De Sanctis, G., Doltra, J., Dumont, B., Fereres, E., Garcia-Vila, M., Gayler, S., Hoogenboom, G., Hunt, L.A., Izaurralde, R.C., Jabloun, M., Jones, C.D., Kersebaum, K.C., Koehler, A.-K., Liu, L., Müller, C., Naresh Kumar, S., Nendel, C., O'Leary, G., Olesen, J.E., Palosuo, T., Priesack, E., Eyshi Rezaei, E., Ripoche, D., Ruane, A.C., Semenov, M.A., Shcherbak, I., Stöckle, C., Stratonovitch, P., Streck, T., Supit, I., Tao, F., Thorburn, P., Waha, K., Wallach, D., Wang, Z., Wolf, J., Zhu, Y., Asseng, S., 2017. The uncertainty of crop yield projections 
